\title{
Prevalence of dual contraceptive use and associated factors among HIV positive women at University of Gondar Hospital, Northwest Ethiopia
}

\author{
Mebratu Mitiku Reta ${ }^{1 *}$, Gizachew Assefa Tessema ${ }^{2}$ and Getachew Shiferaw ${ }^{3}$
}

\begin{abstract}
Objective: Dual contraceptive is the use of male condom besides any modern contraceptive. It reduces parent to child transmission of HIV and other sexually transmitted infections between partners. The aim of this study was to investigate the prevalence and associated factors of dual contraceptive use among HIV positive women at University of Gondar Hospital, North West Ethiopia.

Result: The prevalence of dual contraceptive use was found to be $13.2 \%(95 \% \mathrm{Cl} 10.5,16.0)$. Partner involvement in post-test counseling $[\mathrm{AOR}=3.11(95 \% \mathrm{Cl}=1.74,5.57)]$, open partner discussion on using dual contraceptive $[\mathrm{AOR}=7.84,95 \% \mathrm{Cl}(4.26,14.42)]$, provision of counseling about dual contraception $[\mathrm{AOR}=6.56,95 \% \mathrm{Cl}(3.54,12.18)]$, age $18-24$ years $[\mathrm{AOR}=4.79,95 \% \mathrm{Cl}(1.72,13.32)]$, age $25-34$ years $[\mathrm{AOR}=1.97,95 \% \mathrm{Cl}(1.01,3.85)]$ and being a housewife $[A O R=4.38,95 \% \mathrm{Cl}(1.89,10.16)]$ were significant factors associated with dual contraceptive use. The prevalence of dual contraceptive use was low. This shows, there is a need to in promote partner involvement in HIV testing and counseling by offering counseling session in a couple-basis. It is also necessary for programmers to routinely focus on provision of dual contraception for HIV-infected women and Integration of family planning into HIV care follow-up clinic need to be strengthened.
\end{abstract}

Keywords: Dual contraceptive, HIV/AIDS, Women, Ethiopia

\section{Introduction}

In 2017, about 37 million people were living with HIV/ AIDS in the world. More than two-third of them were living in sub-Saharan Africa and close to three-fourth of all AIDS related deaths were occurred in this region $[1,2]$. Nearly $92 \%$ of pregnant women living with HIV were also from sub-Saharan Africa [3]. According to the 2011 Ethiopian demographic Health Survey (EDHS), the prevalence of HIV infection in women was 1.9\% [4]. Dual contraceptive can reduce the transmission of resistant strains of HIV between partners [5]. Prevention of unintended pregnancy is the second approach in prevention

\footnotetext{
*Correspondence: mebretann16@gmail.com

${ }^{1}$ Department of Internal Medicine, School of Medicine, University of Gondar, Gondar, Ethiopia

Full list of author information is available at the end of the article
}

of mother to child transmission of HIV (PMTCT) [6]. In doing so, contraceptive use is necessary and suggested by WHO and ministry of Health [7]. However, although HIV-positive women can use most of the available contraceptive methods, including hormonal, intrauterine devices and sterilization method [8], these methods are falling short in preventing transmission of HIV and STIs between partners. The effectiveness of estrogen based hormonal contraceptive is also affected by an interaction with some Antiretroviral (ARV) drugs such as Non Nucleotide reverse transcriptase inhibitors (NNRTIs) and protease inhibitors (PIs) [9]. As a result, an HIV-infected woman requires barrier methods such as, condom on top of the methods they used for the prevention of unintended pregnancies. Dual protection by using condom and any modern contraceptive method has paramount benefit for HIV positive women. Therefore, the study can 
provide evidence for the planners, officers and care providers in order to design appropriate interventions.

\section{Main text \\ Methods \\ Study deign and participants}

An institution based cross-sectional study was conducted at the University of Gondar Hospital, Northwest Ethiopia. The Hospital is located in Gondar town, $737 \mathrm{~km}$ from Addis Ababa. The hospital is serving for more than five million people in the catchment area. It has more than 600 inpatient admissions. There were a total of 6232 HIV patients at ART follow up clinic during data collection. The number of HIV positive women attending HIV care was 3219. HIV positive married women attending chronic HIV care follow up at the ART clinic during data collection were participated in the study. Pregnant HIV positive women were excluded from the study.

\section{Sampling and sample size calculation}

The sample size was determined using single population proportion formula by considering the following assumptions. Prevalence $(\mathrm{P})$ was taken as $50 \%$, since there was no study in Ethiopia. The 95\% confidence interval, 4\% level of precision and 5\% non-response rate was considered to get a sample size of 630 . Simple random sampling technique was used to select the study participants from July to August 2014.

\section{Data collection techniques and procedures}

Face to face interviewer administered questionnaire containing socio demographic and clinical characteristics and information on contraceptive use was used for data collection. Participants chart was also reviewed to record their date of HIV diagnosis, WHO clinical stage and current CD4 count. Once the participant interviewed, chart was labeled using a code to avoid repetition. The questionnaire was prepared in English and translated to Amharic and then back to English to maintain its consistency. Four trained nurses having a bachelor degree and one supervisor were involved in the data collection.

\section{Data analysis}

The filled questionnaires were checked for completeness, cleaned manually, pre-coded and entered to EPI Info version 3.5.3 statistical software before exported to SPSS version 20 for analysis. Descriptive and summary statistics were used to explain the study population with respect to the associated factors. Binary logistic regression was used primarily to check factors associated with the outcome variable and variables having $\mathrm{p}$ value of less than 0.2 were fitted into the multivariable logistic regression model. Backward stepwise multiple logistic regression model was fitted to identify the determinants of dual contraceptive utilization practice. Crude odds ratio with 95\% CI was computed. Adjusted odds ratios with $95 \% \mathrm{CI}$ were calculated. Statistical significance was inferred at a $P$ value of $<0.05$.

\section{Results}

A total of 619 women were participated in the study with a response rate of $98.25 \%$. The majority (92.9\%) were urban residents. The mean age of the respondents was 32.26 [SD 6.3] years. One Hundred seventy (27.6\%) of women were house wives. Five hundred ninety-three (95.8\%) of women received post test counseling service. Only $38.1 \%$ percent of HIV positive women had discussion with their health care provider about dual contraceptive. Majority (65\%) of the study participants had a CD4 count between 201 and 350 cells $/ \mathrm{mm}^{3}$ (Table 1 ).

Five hundred twenty-five (84.8\%) women had ever given birth. One hundred thirteen (18.3\%) and 36 (5.8\%) had history of abortion and still birth respectively. Six hundred four (97.6\%) of the respondents were informed about modern contraceptive methods. Depo-Provera, Oral contraceptive pills and male condom were the most recognized family planning methods by the women $(92.9 \%, 91.1 \%$ and $84.3 \%)$ respectively. Two hundred forty-one (38.9\%) heard about dual contraceptive methods. About (38.1\% and $33.9 \%)$ of the study participants had discussion with health care worker and with their partner about the use of dual contraceptives respectively. Male condom was the most commonly used contraceptive by $33.12 \%$ of their partners (Table 2 ).

Two hundred sixty-two (42.3\%) respondents were current users of modern contraceptive methods. Male condoms were the most commonly used method. In this study the prevalence of dual contraceptive was 13.2\% [95\% CI $(10.5,16.0)]$. Among those who were using the dual contraceptives, majority of them used condom with injectable 57 (69.5\%). About 66\% of them were using condom consistently. Fear of side effects, partner disapproval to use condom and lack of women's self-interest to use condom were major reasons not to use dual contraceptive. However, they were not statistically significant Multivariable logistic regression indicated that, partner involvement in post test counseling, open discussion between partners on dual contraceptive, counseling by health care providers ( $\mathrm{HCP}$ ) about its benefit, Age, and being a housewife were significant factors associated with dual contraceptive use. Partner involvement in post test counseling had three times more odds of dual contraceptive utilization than those who did not have any partner involvement $[\mathrm{AOR}=3.11(95 \% \mathrm{CI}=1.74,5.57)]$. Those who had Open partner discussion about dual contraceptive use were almost 8 times more odds of dual 
Table 1 Scio-demographic and clinical characteristics of HIV positive women at University of Gondar referral Hospital, North west Ethiopia, $2014(n=619)$

\begin{tabular}{|c|c|c|c|c|}
\hline Variables & Category & Frequency & Dual contraceptive use & Percent \\
\hline \multirow[t]{2}{*}{ Residence } & Urban & 575 & 76 & 13.2 \\
\hline & Rural & 44 & 6 & 13.6 \\
\hline \multirow[t]{3}{*}{ Age in years } & $18-24$ & 56 & 12 & 21.43 \\
\hline & $25-34$ & 341 & 52 & 15.25 \\
\hline & $\geq 35$ & 222 & 18 & 8.1 \\
\hline \multirow[t]{3}{*}{ Religion } & Orthodox & 546 & 77 & 14.1 \\
\hline & Muslim & 58 & 4 & 6.9 \\
\hline & Others $^{\mathrm{a}}$ & 15 & 1 & 6.6 \\
\hline \multirow[t]{4}{*}{ Ethnicity } & Amhara & 560 & 76 & 13.6 \\
\hline & Kemant & 25 & 2 & 8 \\
\hline & Tigre & 26 & 4 & 15.4 \\
\hline & Others $^{b}$ & 8 & 0 & 0.0 \\
\hline \multirow[t]{5}{*}{ Educational status } & Can't read and write & 139 & 25 & 18 \\
\hline & Read and write only & 22 & 2 & 9.1 \\
\hline & Primary school & 190 & 165 & 86.84 \\
\hline & Secondary school & 195 & 171 & 87.7 \\
\hline & TVET/College/University & 73 & 6 & 8.22 \\
\hline \multirow[t]{4}{*}{ Occupation } & House wife & 171 & 40 & 23.4 \\
\hline & Merchant & 153 & 20 & 13.1 \\
\hline & Daily laborer & 118 & 12 & 10.2 \\
\hline & Government employee & 177 & 10 & 5.65 \\
\hline \multirow[t]{5}{*}{ Partner's occupation } & Merchant & 151 & 18 & 11.9 \\
\hline & Daily laborer & 150 & 26 & 17.3 \\
\hline & Farmer & 96 & 10 & 10.42 \\
\hline & Government employee & 196 & 27 & 13.8 \\
\hline & Others $^{c}$ & 25 & 1 & 4.0 \\
\hline \multirow[t]{3}{*}{ Duration of HIV follow up (months) } & $<6$ & 33 & 4 & 12.1 \\
\hline & $6-24$ & 109 & 11 & 10.1 \\
\hline & $>24$ & 477 & 67 & 14.05 \\
\hline \multirow[t]{2}{*}{ Received post test counseling } & Yes & 477 & 70 & 14.7 \\
\hline & No & 142 & 12 & 8.45 \\
\hline \multirow[t]{2}{*}{ Counseled by HCP about dual contraceptive use } & Yes & 236 & 65 & 27.54 \\
\hline & No & 383 & 17 & 4.44 \\
\hline \multirow{2}{*}{ HIV status disclosed to partner } & Yes & 452 & 72 & 15.9 \\
\hline & No & 167 & 10 & 6.0 \\
\hline \multirow[t]{2}{*}{ Partner involved in posttest counseling } & Yes & 245 & 56 & 22.86 \\
\hline & No & 374 & 26 & 6.95 \\
\hline \multirow[t]{3}{*}{ Partners HIV status } & Reactive & 356 & 66 & 18.54 \\
\hline & Non reactive & 19 & 1 & 5.3 \\
\hline & Unknown & 244 & 15 & 6.15 \\
\hline \multirow[t]{4}{*}{ WHO Clinical stage } & । & 153 & 27 & 17.65 \\
\hline & $\|$ & 112 & 12 & 10.71 \\
\hline & III & 282 & 36 & 12.77 \\
\hline & IV & 72 & 7 & 9.72 \\
\hline \multirow[t]{3}{*}{ Recent CD4 count (cells/mm³) } & $<200$ & 84 & 5 & 5.95 \\
\hline & $201-350$ & 207 & 31 & 15 \\
\hline & $>350$ & 328 & 46 & 14 \\
\hline
\end{tabular}

${ }^{a}$ Catholic, Wakefata, ${ }^{b}$ Oromo, Gurage, ${ }^{c}$ Jobless, private employee 
Table 2 Information on modern contraceptive methods among HIV positive women at University of Gondar referral Hospital, North west Ethiopia, 2014 ( $n=619)$

\begin{tabular}{lcc}
\hline Variables & Frequency & Percentage \\
\hline Informed regarding modern contraceptive methods & \\
OCP & 564 & 91.1 \\
IUCD & 443 & 71.6 \\
Depo provera & 575 & 92.9 \\
Norplant & 446 & 72.1 \\
Female condom & 122 & 19.7 \\
Female sterilization & 94 & 15.2 \\
Male condom & 522 & 84.3 \\
Male sterilization & 84 & 13.6 \\
Emergency pills & 128 & 20.7 \\
Ever heard about modern contraceptive & 606 & 97.9 \\
Ever heard about dual contraceptive & 241 & 38.9 \\
Counseled about dual contraceptive by HCP & 236 & 38.1 \\
Discussed about dual contraceptive with & 210 & 33.9 \\
partner/husband & & \\
\hline
\end{tabular}

contraceptive use than who never discussed $[\mathrm{AOR}=7.84$, $95 \%$ CI $(4.26,14.42)]$. Women counseled by health care provider to use dual contraceptive were 7 times more odds to use $[\mathrm{AOR}=6.56,95 \% \mathrm{CI}(3.54,12.18)]$. Age 18-24 years were close to five times more odds of using dual contraceptive $[\mathrm{AOR}=4.79,95 \% \mathrm{CI}(1.72,13.32)]$ and those age 25-34 years had two times more odds of dual contraceptive use than age 35 and above $[\mathrm{AOR}=1.97$, 95\% CI $(1.01,3.85)]$. Housewives were 4.4 times more odds of using dual contraceptive than government employees $[\mathrm{AOR}=4.38,95 \%$ CI $(1.89,10.16)]$ (Table 3$)$.

\section{Discussion}

The use of dual contraceptive is very important for effectiveness of PMTCT program. However, this study revealed that the prevalence of dual contraceptive utilization was low. Similar result was also reported in Kenya (13.5\%) [10], Uganda (17\%) [11], Uganda (17\%) [12], Zambia (17\%) [13]. This may be due you to the variation in time of enrolment in HIV care and the time that the

Table 3 Logistic regression analysis of variables on dual contraceptive practice among HIV positive women at University of Gondar referral Hospital, North west Ethiopia, $2014(n=619)$

\begin{tabular}{|c|c|c|c|c|c|c|}
\hline \multirow[t]{2}{*}{ Variables } & \multirow[t]{2}{*}{ Categories } & \multicolumn{2}{|c|}{$\begin{array}{l}\text { Dual } \\
\text { contraceptive } \\
\text { use }(n=619) \\
\end{array}$} & \multirow[t]{2}{*}{ COR $(95 \% \mathrm{Cl})$} & \multirow[t]{2}{*}{ AOR $(95 \% \mathrm{CI})$} & \multirow[t]{2}{*}{$P$ value } \\
\hline & & Yes & No & & & \\
\hline \multirow[t]{3}{*}{ Age in years } & $18-24$ & 12 & 44 & $3.1(1.39,6.88)$ & $4.79(1.72,13.32)$ & 0.003 \\
\hline & $25-34$ & 52 & 29 & $2.04(1.16,3.59)$ & $1.97(1.01,3.85)$ & 0.048 \\
\hline & $\geq 35$ & 18 & 204 & 1 & 1 & \\
\hline \multirow[t]{4}{*}{ Occupation } & Housewife & 40 & 131 & $5.1(2.46,10.56)$ & $4.38(1.89,10.16)$ & 0.001 \\
\hline & Merchant & 20 & 133 & $2.51(1.14,5.55)$ & $1.99(0.82,4.88)$ & \\
\hline & Daily laborer & 12 & 106 & $1.89(0.79,4.53$ & $1.43(0.54,3.87)$ & \\
\hline & Government employee & 10 & 167 & 1 & 1 & \\
\hline \multirow[t]{2}{*}{ Counseled by HCP about dual contraceptive } & Yes & 65 & 171 & $8.18(4.66,14.38)$ & $6.56(3.54,12.18)$ & $<0.001$ \\
\hline & No & 17 & 366 & 1 & 1 & \\
\hline \multirow[t]{2}{*}{ HIV status disclosed to partner } & Yes & 72 & 380 & $2.98(1.50,5.91)$ & $1.12(0.48,2.58)$ & \\
\hline & No & 10 & 157 & 1 & 1 & \\
\hline \multirow[t]{2}{*}{ Partner involved in post test counseling } & Yes & 56 & 189 & $3.97(2.41,6.52)$ & $3.11(1.74,5.57)$ & $<0.001$ \\
\hline & No & 26 & 348 & 1 & 1 & \\
\hline \multirow[t]{2}{*}{ Ever heard about dual contraceptive } & Yes & 82 & 524 & $7.84(4.46,13.78)$ & $1.19(0.10,14.33)$ & \\
\hline & No & 0 & 13 & 1 & 1 & \\
\hline \multirow[t]{2}{*}{ Discussed with partner about dual contraceptive } & Yes & 60 & 150 & $7.04(4.17-11.88)$ & $7.84(4.26,14.42)$ & $<0.001$ \\
\hline & No & 22 & 387 & 1 & 1 & \\
\hline \multirow[t]{2}{*}{ Ever gave birth } & Yes & 74 & 451 & $1.76(0.82,3.79)$ & $1.51(0.58,3.96)$ & \\
\hline & No & 8 & 86 & 1 & 1 & \\
\hline \multirow[t]{3}{*}{ Most recent CD4 count (cells $/ \mathrm{mm}^{3}$ ) } & $<200$ & 5 & 79 & 1 & & \\
\hline & $200-350$ & 31 & 176 & $2.76(1.04,7.42)$ & $1.57(0.51,4.80)$ & \\
\hline & $\geq 350$ & 46 & 282 & $2.58(0.99,6.71)$ & $1.19(0.40,3.52$ & \\
\hline
\end{tabular}


study was conducted (16). As compared to the study in Ireland (22\%) [14], Nigeria (25.1\%) [15], Zambia (25\%) [16], India (23\%) [16], South Africa (22\%) [17], Southwest Ethiopia (19.8\%) [18], Thailand (29.6\%) [19], Tanzania (33\%) [20], Kenya [21] and Fitche hospital, Ethiopia (32\%) [22] our finding is lower. This finding was also much lower than the finding of the study done in Nigeria and United States of America where (50\% and 59.7\%) of HIV positive women were using dual contraceptive methods respectively $[23,24]$. This may be due to the fact that women in the study area may lack negotiation skill as a result of socio-cultural influence that hinders open partner discussion about contraceptive. It may also be due to lack of knowledge about dual contraceptive when compared with women in Ireland, India, South Africa and Nigeria.

Concerning the factors affecting dual contraceptive methods utilization, partner involvement in HIV testing and counseling was found to be significant factor to use dual contraceptive methods by HIV positive women. Those who were tested and counseled together with their partner were 3.1 times more odds to use dual contraceptive $[\mathrm{AOR}=3.11(95 \% \mathrm{CI}=1.74,5.57)]$. This finding is supported by a survey conducted in Addis Ababa [25] and India [26]. This suggests that testing and counseling partners together encourages them to have open discussion while choosing the appropriate contraceptive methods they use. An open partner discussion on choosing contraceptive was significantly associated with dual contraceptive use. Those who ever had open discussion were almost 8 times more odds of dual contraceptive use than who never discussed $[\mathrm{AOR}=7.84,95 \% \mathrm{CI}(4.26,14.42)]$. This was again supported by a study conducted in Addis Ababa [25], Tanzania [20], Bahir Dar [27], south west Ethiopia [28] and Tigray region [29]. This suggests that, creating an open discussion between partners about contraceptive choice and its benefit is advantageous. Counseling by health care provider was significant factor to use dual contraceptive among HIV positive women. Those counseled by health care provider to use dual contraceptive were six and half times more odds of using dual contraceptive $[\mathrm{AOR}=6.56,95 \% \mathrm{CI}(3.54,12.18)]$. This agrees with a study conducted in Lusaka, Zambia [13] and India [26], Tanzania [20], Kenya [21] and Bahir Dar [27]. This strongly indicates that counseling of HIV positive women can improve the utilization of dual contraceptive use in preventing unintended pregnancy and sexually transmitted infections. It also suggests that health care providers need to focus on counseling on dual contraceptives and its benefit to HIV positive women attending care at ART clinic. This study also showed that age of the respondents was one of the important factors. Those women age $18-24$ years $[\mathrm{AOR}=4.79,95 \% \mathrm{CI}(1.72,13.32)]$, age
$25-34$ years $[\mathrm{AOR}=1.97,95 \% \mathrm{CI}(1.01,3.85)]$ were having more odds of dual contraceptive use than those above 35 years old. This was supported by the finding of the study in Northern Uganda [30]. This finding was also supported by the finding in a systematic review done by Marge Berer [31]. It may be due to the fact that those young women may not be interested to have child at this age and may have better understanding on the benefit of using dual contraceptive. However, the finding of this study was not consistent with the finding of the study conducted in southwest Ethiopia [28]. This variation may be due to the fact that the difference in the study design and sample size; mixed method was used in the study conducted in southwest Ethiopia with small sample size. Being a house wife was significantly associated with dual contraceptive use. Those housewife in their occupation were about 4.5 times more odds of using dual contraceptive compared to government employees $[\mathrm{AOR}=4.38$, $95 \%$ CI $(1.89,10.16)]$. The reason for this may be due to economical concern. Housewives do not have their own monthly income and they are dependent on their partner. Due to this, they may believe that they can't afford expenses if they become pregnant and give birth. This assumption is supported by the finding of a study conducted northern Uganda [30] and Southwestern Uganda [32].

\section{Conclusion}

Only small proportion of HIV positive women were using dual contraceptive. Partner involvement in post test counseling, open partner discussion about dual contraceptive, providing counseling by HCP about dual contraceptive, age and occupation of the women were positively associated with dual contraceptive use. Simultaneous HIV testing and counseling of women with their partner, open partner discussion s on family planning choice and provision of counseling by health care providers shall be encouraged.

\section{Limitations}

Major limitations in this study are absence of variables that might have been associated with dual contraceptive use, such as: social support and variables related to mental health. Absence of partner involvement in the study was also another limitation. A cross-sectional study design lacks temporal association. In addition, since the questionnaire covers private issues there might be information bias.

\section{Abbreviations}

AIDS: Acquired Immune deficiency Syndrome; ART: antiretroviral therapy; ARV: antiretroviral; EDHS: Ethiopian Demographic Health Survey; HCP: Health 
Care Provider; HCW: health care worker; PMTCT: Prevention of Mother to Child Transmission; STIs: Sexually Transmitted Infections; TVET:Technical and Vocational Education and Training; WHO: World Health Organization.

\section{Authors' contributions}

MM wrote the proposal, participated in data collection, analyzed the data, drafted the paper and prepared the manuscript. GA and GS approved the proposal with some revisions, participated in data analysis and revised subsequent drafts of the paper. All authors read and approved the final manuscript.

\section{Author details}

${ }^{1}$ Department of Internal Medicine, School of Medicine, University of Gondar, Gondar, Ethiopia. ${ }^{2}$ Department of Reproductive Health, Institute of Public Health, University of Gondar, Gondar, Ethiopia. ${ }^{3}$ Department of Gynecology and Obstetrics, School of Medicine, University of Gondar, Gondar, Ethiopia.

\section{Acknowledgements}

We acknowledge all staffs of University of Gondar, College of Medicine and Health Sciences. In addition; University of Gondar administrative office, data collectors, and all the study participants were highly acknowledged.

\section{Competing interests}

The authors declare that they have no competing interests.

\section{Availability of data and materials}

The datasets used and/or analyzed during the current study are available from the corresponding author on reasonable request.

\section{Consent for publication}

Not applicable.

\section{Ethics approval and consent to participate}

Ethical clearance was obtained from University of Gondar Institutional review board following the Ethiopian National research Ethics review guideline of the federal ministry of science and technology. Permission letter was obtained from University of Gondar referral hospital chief executive officer. Participants were fully informed about the purpose of the study before the beginning of the interview and verbal informed consent was obtained.

\section{Funding}

This research received no specific Grant from any funding agency in the public, commercial or not-for-profit sectors. But the financial backing of this research was provided by University of Gondar as a grant to its staff. The funder has no role in the publication process.

\section{Publisher's Note}

Springer Nature remains neutral with regard to jurisdictional claims in published maps and institutional affiliations.

Received: 21 November 2018 Accepted: 8 January 2019

Published online: 18 January 2019

\section{References}

1. UNAIDS. Global HIV statistics. In: Fact sheet 2018. 2017.

2. Amuche NJ, Emmanuel El, Innocen NE. HIV/AIDS in sub-Saharan Africa: current status, challenges and prospects. Asian Pac J Trop Dis. 2017;7(4):239-56.

3. UNAIDS. Regional HIV/AIDS fact sheet: sub-Saharan Africa. UNAIDS. p. $1-3$.

4. CSA. Ethiopian Demographic and Health Survey (EDHS) 2011. Addis Ababa, Ethiopia; 2012.

5. Raifman J, Chetty T, Tanser F, Mutevedzi T, Matthews PHK, Pillay D. Preventing unintended pregnancy and HIV transmission: effects of the HIV treatment cascade on contraceptive use and choice in rural KwaZuluNatal. J Acquir Immune Defic Syndr. 2014;67(4):218-27.

6. FHAPCO. Guidelines for prevention of mother-to-child transmission of HIV. Addis Ababa, Ethiopia; 2007.
7. Health FDRoEMo. Competency based National Comprehensive PMTCT/ MNCH training participants manual. Addis Ababa; 2017.

8. King-Spooner S. HIV prevention and the positive population. Int J STD AIDS. 1999;10(3):141-50.

9. Agboghoroma CO. Contraception in the context of HIV/AIDS. Afr J Reprod Health. 2011;15(3):15-23.

10. Mutiso SM, Kinuthia J, Qureshi Z. Contraceptive use among HIV infected women attending Comprehensive Care Centre. East Afr Med J. 2008:85(4):171-7.

11. Nattabi B, Li J, Thompson SC, Orach CG, Earnest J. Family planning among people living with HIV in post-conflict Northern Uganda: a mixed methods study. Confl Health. 2011;5:18.

12. Magala I, Onega L, Rose N, Patrick S. Factors influencing contraceptive uptake among sexually active HIV positive clients in TASO Masaka, Uganda. J Public Health Policy Plan. 2017;1(2):46-9.

13. Chibwesha CJ, Li MS, Matoba CK, Mbewe RK, Chi BH, Stringer JSA, Stringer EM. Modern contraceptive and dual method use among HIV-infected women in Lusaka, Zambia. Infect Dis Obstetr Gynecol. 2011;2011:8.

14. Murphy D, Lynch M, Desmond N, Mulcahy FM. Contraceptive practices in HIV seropositive females in Ireland. Int J STD AIDS. 1993;4(2):107-9.

15. Ezugwu EC, Nkwo PO, Agu PU, Ugwu EO, Asogwa AO. Contraceptive use among HIV-positive women in Enugu, southeast Nigeria. Int J Gynaecol Obstetr. 2014;126(1):14-7.

16. Hancock NL, Chibwesha CJ, Bosomprah S, Newman J, Mubiana-Mbewe M, Sitali ES, Bolton-Moore C, Mbwili-Muleya C, Chi BH. Contraceptive use among HIV-infected women and men receiving antiretroviral therapy in Lusaka, Zambia: a cross-sectional survey. BMC Public Health. 2016;16:392.

17. Morroni C, Myer L, Mlobeli R, Gutin S, Grimsrud A. Dual protection among South African women and men: perspectives from HIV care, family planning and sexually transmitted infection services. Cape Town: University of Cape Town; 2007.

18. Mariam W, Erashi M, Tesso F, Tema Beyene T. Dual-contraceptive method utilization and associated factors among HIV positive women attending art clinic in Gebretsadik Shawo Hospital, SNNPR, South West Ethiopia. J Women's Health Care. 2015;4:2167.

19. Munsakul W, Lolekha R, Kowadisaiburana B, Roongpisuthipong A, Jirajariyavej S, Asavapiriyanont S, Hancharoenkit U, Baipluthong B, Pattanasin S, Martin M. Dual contraceptive method use and pregnancy intention among people living with HIV receiving HIV care at six hospitals in Thailand. Reprod Health. 2016;13:8.

20. Damian DJ, George JM, Martin E, Temba B, Msuya SE. Prevalence and factors influencing modern contraceptive use among HIV-positive women in Kilimanjaro region, northern Tanzania. Contracept Reprod Med. 2018;3:7.

21. Mulongo AM, Lihana RW, Githuku J, Gura Z, Karanja S. Factors associated with uptake of dual contraception among HIV-infected women in Bungoma County, Kenya: a cross-sectional study. Pan Afr Med J. 2017;10:11604.

22. Demissie DB, Girma T, Abdissa G. Dual contraceptive utilization and associated factors among people living with HIV attending ART clinic in Fitche Hospital, Ethiopia. J Health Med Nurs. 2015;2015:20.

23. Ogbe A, Mutihir J. Pattern of contraception among HIV positive women in Jos University Teaching Hospital. Nigerian J Med. 2012;21 (1):11-5.

24. Sutton MY, Zhou W, Frazier EL. Unplanned pregnancies and contraceptive use among HIV-positive women in care. PLoS ONE. 2018;13(5):e0197216.

25. Asfaw HM, Gashe FE. Contraceptive use and method preference among HIV positive women in Addis Ababa, Ethiopia: a cross sectional survey. BMC Public Health. 2014;14:556.

26. Chakrapani V, Kershaw T, Shunmugam M, Newman PA, Cornman DH, Dubrow R. Prevalence of and barriers to dual-contraceptive methods use among married men and women living with HIV in India. Infect Dis Obstet Gynecol. 2011;3:7.

27. Kebede HG, Nahusenay H, Birhane Y, Tesfaye DJ. Assessment of contraceptive use and associated factors among HIV positive women in Bahir-Dar Town, Northwest Ethiopia. Open Access Library Journal. 2015;2(10):19.

28. Erashi MWM, Tesso FY, Beyene TT. Dual-contraceptive method utilization and associated factors among HIV positive women attending art clinic in Gebretsadik Shawo Hospital, SNNPR, South West Ethiopia. Women's Health Care. 2015;4:267. 
29. Melaku YA, Zeleke EG. Contraceptive utilization and associated factors among HIV positive women on chronic follow up care in Tigray Region, Northern Ethiopia: a cross sectional study. PLoS ONE. 2014;9(4):e94682.

30. Bongomin F, Chelangat M, Eriatu A, Chan Onen B, Cheputyo P, Godmercy SA, Ekuk E, Idony F, Henry Obol J. Prevalence and factors associated with contraceptive use among HIV-infected women of reproductive age attending infectious disease clinic at Gulu Regional Referral Hospital, Northern Uganda. BioMed Res Int. 2018;2018:8.
31. Berer M. Dual protection: more needed than practised or understood. Reprod Health Matters. 2006;14(28):162-70.

32. Muyindike W, Fatch $R$, Steinfield R, Matthews LT, Musinguzi N, Emenyonu NI, Martin JN, Hahn JA. Contraceptive use and associated factors among women enrolling into HIV care in Southwestern Uganda. Infect Dis Obstetr Gynecol. 2012;2012:9
Ready to submit your research? Choose BMC and benefit from:

- fast, convenient online submission

- thorough peer review by experienced researchers in your field

- rapid publication on acceptance

- support for research data, including large and complex data types

- gold Open Access which fosters wider collaboration and increased citations

- maximum visibility for your research: over $100 \mathrm{M}$ website views per year

At BMC, research is always in progress.

Learn more biomedcentral.com/submissions 